\title{
Colorectal cancer prevention. An approach to increasing compliance in a faecal occult blood test screening programme
}

\author{
A R Hart, J Eaden, S Barnett, A M de Bono, J F Mayberry
}

\begin{abstract}
Study objective-The assessment of the uptake of colorectal cancer screening offered in a workplace setting.

Design-Employees were offered a free faecal occult blood test (Haemoccult). A repeat letter was sent two months later to non-responders. Those with positive tests were invited for colonoscopy. Compliance was measured according to age, sex, and occupational group and the effects of reinviting non-compliers investigated.

Setting-Leicester General Hospital, a large university teaching hospital.

Participants-990 employees aged 41 to 65 years.

Main results-Total compliance was $46 \%$ with women participating more than men $\left(49 \% v 34 \%, \chi^{2}=12.2, \mathrm{p}<0.001\right)$. The difference was mostly because of women aged 41 to $\mathbf{5 0}$ years complying more than their male counterparts $\left(48 \% v 24 \%, \chi^{2}=15.5\right.$, $\mathbf{p}<0.0001)$. Participation was highest in clinical support staff $(56 \%)$, nurses $(52 \%)$, and clerical workers $(46 \%)$. Uptake by doctors (26\%) and managers (26\%) was significantly lower than by clinical support staff and nurses $\left(\chi^{2}>5.5, p<0.02\right)$. Remailing raised compliance slightly from $43.6 \%$ to $46.3 \%$. Four employees (1\%) had positive faecal occult blood tests but three were negative on repeat testing with dietary restrictions.
\end{abstract}

Conclusions-The government favours the development of health promotion programmes as stated in its document "Health at work in the NHS". The response in this study, showed methods to increase compliance must be developed if such programmes are to be successful. As uptake was similar to that in several community based programmes in general practice, workplace based programmes could offer a complementary method of delivering screening.

(F Epidemiol Community Health 1998;52:818-820)

Colorectal cancer is the second commonest malignancy in Britain with over 20000 fatalities each year. ${ }^{1}$ Major public health initiatives are urgently required to help reduce the high morbidity and mortality from the disease. There is currently a call for a national screening programme with faecal occult blood tests, following the publication of two large randomised trials from Nottingham ${ }^{2}$ and Denmark $^{3}$ showing a reduction in mortality of
$15 \%$ and $18 \%$ respectively in those offered screening.

One of the major problems in any screening programme is encouraging participation. A poor compliance means relatively little benefit to the population and a high economic cost. The problem of low uptake was identified in the Nottingham study where although $60 \%$ of the test group completed at least one test, only $38 \%$ completed all the follow up kits at two yearly intervals. ${ }^{2}$ Unfortunately, compliance is also a problem in other smaller community trials where less than $50 \%$ of the population participates when offered through general practitioners. $^{4-10}$ To help raise compliance, alternative methods of delivery must be investigated such as workplace based programmes. On site advertising and word of mouth publicity may encourage participation. An ideal environment to test workplace cancer screening is in the staff of a large teaching hospital. The National Health Service in the United Kingdom employs over a million people so the potential to prevent cancer death if such a service was successful would be large. Furthermore, the government is encouraging the development of such preventative health programmes through its "Health at Work in the NHS" initiative.

\section{Methods}

A total of 990 employees aged 40 to 65 years were invited through a personalised letter to participate in a colorectal cancer screening programme using faecal occult blood tests (Haemoccult). The hospital employs a total of 2362 people, but those under 40 years of age were excluded. The letter was sent jointly from the Departments of Gastroenterology, Human Resources and Occupational Health at the Leicester General Hospital. In addition the project was advertised in the hospital newspaper and additional information was available in the Department of Occupational Health. Those employees who accepted were sent a free Haemoccult pack, which included instructions on how to perform the test. Fresh stool was collected and applied to the cardboard slides from the kit. These were collected on three separate days by the employee and returned to Leicester General Hospital where they were analysed by one investigator (ARH). Slides were not rehydrated and were considered positive if a blue colour appeared on the addition of a solution of hydrogen peroxide and denatured alcohol to the sample.

People with positive faecal occult blood tests were asked to repeat the stool samples avoiding red meat, cauliflower, cabbage, spinach, broc- 
Table 1 Participation with a colorectal cancer screening programme in a university hospital

\begin{tabular}{lrr}
\hline Age (y) & Women (\%) & \multicolumn{1}{c}{ Men (\%) } \\
\hline $41-50$ & $204 / 425(48)$ & $19 / 79(24)$ \\
$51-60$ & $177 / 344(51)$ & $27 / 64(42)$ \\
$61-65$ & $19 / 51(37)$ & $10 / 22(45)$ \\
Total & $400 / 820(49)$ & $56 / 165(34)$
\end{tabular}

Younger women aged 41 to 50 years complied more than their male colleagues $\left(\chi^{2}=15.5, \mathrm{p}<0.0001\right)$. Compliance in men and women aged 51 to 65 years was the same $\left(\chi^{2}<1.9\right.$, NS)

Table 2 Compliance with occupational based screening for colorectal cancer in a university hospital

\begin{tabular}{lrr}
\hline Occupational group & Women (\%) & \multicolumn{1}{c}{ Men (\%) } \\
\hline Clinical support staff & $21 / 38(55)$ & $4 / 7(57)$ \\
Nurses & $209 / 397(53)$ & $4 / 11(36)$ \\
Clerical & $88 / 182(48)$ & $4 / 19(21)$ \\
Non-clinical ancillary staff & $77 / 181(43)$ & $32 / 84(38)$ \\
Doctors & $1 / 2(50)$ & $8 / 33(24)$ \\
Managers & $4 / 20(20)$ & $4 / 11(36)$ \\
\hline
\end{tabular}

Compliance was assessed according to occupation. Doctors participated less than nurses, clerical workers, and clinical support staff $\left(\chi^{2}>4.1, \mathrm{p}<0.05\right)$.

coli, and bananas. Dietary retesting reduces the number of false positives by $60 \% .{ }^{11}$ If any repeat slides were positive, patients were invited to attend for colonoscopy. Patients who had repeat negative slides were told to contact their doctor if in the future they developed symptoms. A further test was offered to these people four months later.

Two months after the initial mailing those who had not requested a test were sent a repeat invitation to participate.

The number of people completing kits was analysed by age, sex, and occupation and tested for significance using a $\chi^{2}$ statistic.

\section{Results}

COMPLIANCE WITH SCREENING

The overall compliance with screening was $46 \%$ (table 1) with women participating more than men $\left(49 \%\right.$ v $\left.34 \%, \chi^{2}=12.2, \mathrm{p}<0.001\right)$. This difference was because of a greater compliance in women aged 41 to 50 years than men of the same age $\left(48 \% v 24 \%, \chi^{2}=15.5\right.$, $\mathrm{p}<0.0001)$. Uptake in men and women was similar in the age groups 51 to $60(42 \%$ v $51 \%$, $\left.\chi^{2}=1.9, \mathrm{NS}\right)$ and 61 to 65 years ( $45 \% v 37 \%$, $\left.\chi^{2} 0=0.4, \mathrm{NS}\right)$.

In women compliance was similar in the age groups 41 to $50(48 \%), 51$ to $60(51 \%)$ and 61 to 65 years $\left(37 \%, \chi^{2}<0.6, \mathrm{NS}\right)$. In men uptake was similar for those in their $50 \mathrm{~s}(42 \%)$ and $60 \mathrm{~s}$ $\left(45 \% \chi^{2}=0.1\right.$, NS) but men in their $40 \mathrm{~s}$ complied less than both the above age groups $\left(24 \%, \chi^{2}>3.9, p<0.05\right)$.

COMPLIANCE ACCORDING TO OCCUPATION

Participation was related to occupational group (table 2). Compliance was highest in clinical support staff $(56 \%)$, nurses $(52 \%)$, and clerical workers $(46 \%)$ and similar between the three groups $\left(\chi^{2}<2.2, \mathrm{NS}\right)$. All the above participated more than doctors $\left(26 \%, \chi^{2}>4.1, \mathrm{p}<0.05\right)$ and managers $\left(26 \%, \chi^{2}>5.5, \mathrm{p}<0.02\right)$ although compliance was statistically similar between clerical workers and managers $\left(\chi^{2}=3.6, \mathrm{NS}\right)$. Compliance in doctors and managers was identical $\left(\chi^{2}=0, N S\right)$. Non-clinical ancillary staff participated less (41\%) than nurses $\left(\chi^{2}=7.9, \mathrm{p}<0.005\right)$ but similar to the other four occupational groups $\left(\chi^{2}<3.3, \mathrm{NS}\right)$.

Compliance was similar between sexes for nurses $\left(\chi^{2}=0.6, \mathrm{NS}\right)$ and for non-clinical ancillary staff $\left(\chi^{2}=0.5, \mathrm{NS}\right)$. Female clerical workers were more likely to participate than male clerical workers $\left(48 \%\right.$ v $\left.21 \%, \chi^{2}=4.1, \mathrm{p}<0.05\right)$. Statistical analysis for compliance in male and female doctors, managers and clinical support staff is inappropriate as the numbers were small.

EFFECT OF REMINDERS

After the reminder letter a further 27 people $(2.7 \%)$ completed tests, which raised compliance from $43.6 \%$ to $46.3 \%$. Reinvitation increased uptake in men by $1.8 \%$ (3 of 165 ) and in women by $2.9 \%$ (24 of 820$)$. No doctors or clinical support staff responded to the second letter. Remailing to the four other occupational groups did produce a small rise in uptake-that is, non-clinical ancillary workers $(4.5 \%)$, managers (3\%), nurses $(2.7 \%)$, and clerical staff $(1.5 \%)$.

\section{PATHOLOGY DETECTED}

Four employees $(1 \%)$ had positive Haemoccult kits, of which three were negative on dietary re-testing. The fourth employee had proctitis at colonoscopy and was treated with corticosteroid enemas.

\section{Discussion}

The study aims were to assess the effectiveness of a workplace based colorectal cancer screening programme in terms of compliance, uptake according to occupational group, and the effects of remailing. The programme met the aims of the government's "Health at Work in the NHS" initiative. The overall compliance was similar to or higher than that in several community studies where the invitation came from general practitioners. ${ }^{4-10}$ The comparable acceptance between community and workplace programmes justifies the latter's development as a method of delivering preventative health care. Employers interested in health care programmes, such as the government, should be made aware of the employee interest that can be generated. As in community based programmes, strenuous efforts need to be made to raise compliance further.

Participation was lowest in doctors and managers, although we decided not to ascertain reasons for non-compliance in a group of medical colleagues to avoid undue harassment. The purpose of this study was not to identify reasons for non-compliance in some groups, but rather to assess whether overall compliance would make an occupation based approach to screening viable. However, in a separate study we investigated non-acceptance, and refusers in a community based scheme in general practice were interviewed. Here 4185 residents of the Leicestershire town of Market Harborough were invited to participate in a faecal occult blood screening programme. The overall compliance was $38 \%{ }^{8}$ and a sample who wrote declining the offer were investigated. ${ }^{12}$ The commonest reasons for non-compliance were 
the stool collection procedure was unpleasant, lack of appreciation of the concept of asymptomatic illness, fear of more tests and surgery, and intercurrent illness. From these responses, we later developed and assessed an educational booklet that raised compliance in men. ${ }^{13}$ This booklet emphasised that healthy asymptomatic people should participate, defined screening, and explained that few would need further investigations. The booklet had not been developed at the time of this workplace scheme, but clearly any future work could include it with the invitation.

In this study, no neoplastic pathology was detected. However, in larger studies one neoplastic lesion is diagnosed in every 100 people screened people over 50 years. ${ }^{2}$ In this project 233 of this age participated so at most we might have found two neoplastic lesions. A study limitation was that in some occupations the number of employees over 40 years of age was small, for example there were only two female consultants over the age of 40 years. However, the study highlighted that occupations need to be more effectively targeted.

There is little other British work that explores the value of colorectal cancer screening programmes at the workplace. Employees over 40 years of age in two English industrial organisations were invited to receive a Haemoccult kit and complete a symptom questionnaire. ${ }^{14}$ The compliance of $51 \%$ was similar to our own with women again participating more than men, although uptake according to age and occupation was not reported.

Screening programmes for other cancers have also looked at ways of improving uptake. In cervical cancer screening, uptake has been raised by telephoning non-compliers, ${ }^{15}$ by sending a specific appointment time for a smear, ${ }^{16}$ and by using educational pamphlets at routine consultations. ${ }^{17}$ In breast cancer screening, to maximise compliance, the Forrest Report recommended that women in the target group are sent a personal invitation from their general practitioner and that an accurate record system is essential to identify, invite, and recall women eligible for screening. ${ }^{18}$ Again inclusion of a specific appointment time for mammography improves uptake compared with an open ended letter. ${ }^{19}$ Factors that are important in breast cancer screening are encouragement by general practitioners, knowledge about the screening programme, and the views of family and friends. ${ }^{20}$ Tagging the clinical notes of noncompliant women and reminding them at routine consultations is effective. ${ }^{21}$ Assessing research to increase compliance is one of the many functions of the National Screening Committee, which advises ministers and the NHS Executive Board on national screening programmes. The committee is chaired by the Chief Medical Officer and includes professionals from public health, research and development groups, primary care, nursing, economists and consumer and ethical groups. The committee informs government on the clinical and cost effectiveness of screening programmes, implementation, and how programmes can be assessed and monitored. One of their key func-

\section{KEY POINTS}

- The government encourages workplace based health initiatives.

- A hospital based screening programme for colorectal cancer recruited nearly half the eligible workforce.

- Compliance was highest in women.

- Compliance was lowest in doctors and managers.

tions is to emphasise the need for research into screening and for analytical work to make the best use of this research. Clearly this committee will need to consider methods of delivering colorectal cancer screening if a decision to institute a national programme is taken. Workplace based schemes may be an option the group could consider. We would like to thank staff of the Gastroenterology Unit,
Occupational Health Department and the Directorate of Occupational Health Department
Human Resources for their help.

Funding: the Directorate of Human Resources.

Conflicts of interest: none.

1 Office of Population Censuses and Surveys. Mortality statistics 1990. Series DH2,17. London: HM Stationary Office, tics 1990.

2 Hardcastle JD, Chamberlain JO, Robinson ME, et al. Randomised control trial of faecal occult blood screening for colorectal cancer. Lancet 1996;348:1472-7.

3 Kronborg O, Fenger C, Olsen J, et al. Randomised study of Kronborg O, Fenger C, Olsen J, et al. Randomised study of
screening for colorectal cancer with faecal occult blood. screening for colorectal canct

Lancet 1996;348:1467-71.
4 Farrands PA, Griffiths RL, Britton DC. The Frome Experiment-Value of screening for colorectal cancer. Lancet $1981 ; \mathrm{i}: 1231-2$.

5 Hobbs FDR, Cherry RC, Fielding JWL, et al. Acceptability of opportunistic screening for occult gastrointestinal blood loss. BMF 1992;304:483-6.

6 Lallemand RC, Vakil PA, Pearson P, et al. Screening for asymptomatic bowel cancer in general practice. BMF 1984; 288:31-3.

7 Mant D, Chivers A, Fuller A, et al. Patient compliance with colorectal cancer screening in general practice. $\mathrm{Br} \mathcal{F} \mathrm{Gen}$ Pract 1992;42:18-20.

8 Hart AR, Gay SP, Donnelly A, et al. Screening for colorectal cancer in Market Harborough, UK: a community-based cancer in Market Harborough, UK: a community-base
programme. Eur $₹$ Gastroenterol Hepatol 1994;6:519-22.

9 Nichols S, Koch E, Lallemand RC, et al. Randomised trial of compliance with screening for colorectal cancer. BMF 1986;293:107-10.

10 Million R, Howarth J, Turnberg E, et al. Faecal occult blood testing for colorectal cancer in general practice. The Practitioner 1982;226;659-61.

11 Thomas WM, Pye G, Hardcastle JD, et al. Role of dietary restriction in Haemoccult screening for colorectal cancer. Brf Surg 1986:76:976-8

12 Hynam KA, Hart AR, Gay SP, et al. Screening for colorectal cancer:reasons for refusal of faecal occult blood testing in a general practice in England. $\mathcal{F}$ Epidemiol Community Health 1995;49:84-6.

13 Hart AR, Barone TL, Gay SP, et al. The effect on compliance of a health education leaflet in colorectal cancer screening in general practice in central England. $\mathcal{f}$ Epidemiol Community Health 1997;51:187-91.

14 Silman AJ, Mitchell P, Nichols RJ, et al. Self-reported dark red bleeding as a marker comparable with occult blood testing in screening for large bowel neoplasms. Br F Surg testing in screenin

15 McDowell I, Newell C, Rosser W. Computerised reminders to encourage cervical screening in family practice $\mathcal{F}$ Fam Pract 1989;28:420-4.

16 Wilson A, Leeming A. Cervical cytology screening: a comparison of two call systems. BMF 1987;295:181-2.

7 Cockburn J, Hirst S, Hill D, et al. Increasing cervical screening in women of more than 40 years of age: an intervention in general practice. Med $\mathcal{F}$ Aust 1990;152:190-4.

18 Forrest P. Breast cancer screening. Report to the health ministers of England, Wales, Scotland and Northern Ireland, by a working group chaired by Professor Sir Patrick Forrest. London: HMSO, 1986.

19 Williams EMI, Vessey MP. Randomised trial of two strategies offering women mobile screening for breast canstrategies offering women

20 Blamey RW, Wilson ARM, Patnick J, et al. Screening for Blamey RW, Wilson ARM, Patnick J,
breast cancer. $B M \mathcal{F} 1994 ; 309: 1076-9$.

21 Becker DM, Gomez EB, Kaiser DL, et al. Improving preventive care at a medical clinic: How can the patient help? Am f Prev Med 1989;5:353-9. 